\title{
Effects of rational psychotherapy on emotional state and cognitive attitudes of patients with neurotic disorders
}

\author{
Irina Skirtach ${ }^{1 *}$, Natalya Klimova ${ }^{2}$, Alexander Dunayev ${ }^{2}$, and Victoria Korkhova ${ }^{2}$ \\ ${ }^{1}$ Southern Federal University, Academy of Psychology and Pedagogy, Psychophysiology \\ and Clinical Psychology Department, 344006 Rostov-on-Don, Russian Federation \\ ${ }^{2}$ Don State Technical University, Faculty of Psychology, Pedagogy and Defectology, \\ Department of Psychophysiology and Clinical Psychology, 344000 Rostov-on- \\ Don, Russian Federation
}

\begin{abstract}
Development of a neurotic disorder is a result of the formation of the non-adaptive cognitive structures. Each structure conceptualizes the particular nature of perception, gained experience, specific features of the experience understanding, as well as human behavior. As a result of such cognitive structures, automatic thoughts, cognitive biases, and inadequate emotional sufferings occur that determine the choice of maladaptive behavioral strategies. Unconscious nonrational attitudes exacerbate the emotional state resulting in crystallization of non-adaptive behavioral patterns and development of a neurotic disorder. Within the framework of this study, the special focus will be on the examination of the changes that were observed in emotional state and cognitive attitudes of the patients before and after taking treatment in a hospital. Enrolled set consisted of 60 people with different forms of a neurotic disorder aged 25-44 years $(\mathrm{M}=$ $35.8, \mathrm{SD}=5.8(36.7 \% \mathrm{men}))$. The experimental group included 30 people. Unlike the control group, the standard regimen of drug treatment was supplemented with the rational psychotherapy for these patients.
\end{abstract}

\section{Introduction}

Examination of the dynamics of the psychological characteristics of patients with the various forms of a neurotic disorder is deemed to be a highly topical issue. Formation of the dynamics picture of the patients' emotional state and cognitive attitude parameters will allow to differentiate prospects for use of rational psychotherapy in the patients with various forms of neurosis and to develop adequate psychotherapeutic programs for the purpose of the prompt social-psychological recovery.

In terms of the cognitive concept, a neurotic disorder is understood as a result of forming non-adaptive cognitive structures. These structures make up experience, perception, comprehension, emotions, and personality behavior. Automatic thoughts, systematic cognitive errors, and altered fundamental emotions that determine non-adaptive behavior

\footnotetext{
* Corresponding author: limpopo-is@,yandex.ru
} 
strategies are the derivatives of the cognitive structures [1]. Neurotic disorder has a number of characteristics that distinguish it from other mental disorders [2, 3]. Firstly, the abnormalities that occur with these disorders are completely reversible, they disappear after clinical recovery regardless of their duration. Secondly, the disease is psychogenic in its nature. Thirdly, the clinical manifestations of neuroses are characterized by specificity, and they consist in emotionally affective and somatogenic autonomic dysfunctions.

Depression, asthenia, and irresoluteness, fears and phobia, inability to enjoy (anhedonia), anguish and anxiety - this is not the whole list of affective symptoms which is the basis for determining the forms of neurotic disorders.

Altered cognitions underlying this disorder lead to misperceptions, consequently, a patient has inappropriate emotional responses (T. M. Lavrinovich, A. Babl, M. Holtforth, J. C. Perry, N. Schneider, E. Dommann) $[4,5]$.

Non-adaptive errors in perception of reality (dysfunctional attitudes according to A. Beck, or nonrational attitudes according to A. Ellis), their unrealistic character, discrepancy with the reality, irrationality distort the perception and self-evaluation, evaluation of other people and surrounding community and thereby affect other areas of mental health and components (emotional, behavioral) of the personal attitude system triggering the emergence of neurotic and psychosomatic disorders [6].

Prescription of drugs is the main (dominant) treatment method for neurotic disorders in hospital environment. In some cases, it is combined with physiotherapy, exercise therapy, acupuncture, herbal therapy, as well as psychotherapy. The psychotherapist's task is to help patients in an adequate, correct expressing their own feelings, sensations. As a result, extraction of the process development etiologic factor, clarification of the life experience features, determination of the most unfavorable, negative life opportunities become possible. In order to eliminate some neurotic disorder manifestations, psychologist can use explanations in his/her work with patients. The only thing that matters is that explanations be logically reasoned. A similar method is commonly known as "rational psychotherapy" in medical practice. The most popular methods in rational psychotherapy include the approaches of P. Dubois, A. Ellis, A. Beck, J. Moreno [7-11].

In this paper, the examination of the dynamics of emotional state and cognitive attitudes of patients with different forms of a neurotic disorder is intended to form an understanding of opportunities and limitations to use the rational psychotherapy methods. This enables to draw up an optimal scheme of psychocorrective and recovery work by forming the groups of patients with high sensitivity to the application of rational psychotherapy methods taking into account the form of a neurotic disorder, and more accurately predict the expected progress of patients' state.

\section{Study procedure and methods}

Enrolled set consisted of 60 people (patients of State Budgetary Healthcare Institution "Specialized Psychoneurological Hospital" of the Ministry of Health of the Krasnodar Territory): 38 women, 22 men, aged $25-44$ years $(\mathrm{M}=35.8, \mathrm{SD}=5.8(36.7 \% \mathrm{men}))$ that corresponds to a young age according to WHO age grouping of population. The patients with the following diagnoses were included in the groups: F 43.22 Mixed anxiety and depressive reaction induced by adjustment disorder (CTDRa) - 20 persons; F 48.0 Neurasthenia (NEVR) - 20 persons; F 41.2 Mixed anxiety and depressive disorder (CTDR) -20 persons. In addition to the above, the control and experimental groups, equal in number, were composed of the patients. The groups were different in that the standard regimen of drug treatment was supplemented with rational psychotherapy for the experimental group. The subjects of the experimental group received the complete course of individual counseling over a month consisting of 14 sessions each of duration 1.5 hours. 
The study methods included: questionnaire method, scaling, statistical methods (NOVA analysis of variance, Fisher post-hoc analysis). The methodological tools are presented by the following techniques: Beck's Depression Inventory, Beck's Anxiety Scale, JanoffBulman's World Assumptions Scale (adapted and re-standardized by M.A. Padun, A.V. Kotelnikova), Aaron Beck and Arlene Weissman Dysfunctional Attitudes Scale.

The following assumptions were checked: 1) the dynamics of the anxiety and depression level, changing nature of the world assumptions, and intensity of dysfunctional attitudes in response to rational psychotherapy are different in the patients with different forms of neurotic disorders; 2) the effect of rational psychotherapy on the anxiety and depression level, nature of the world assumptions, and intensity of dysfunctional attitudes differs in the patients with neurotic disorders depending on their educational level.

\section{Discussion}

Psychodiagnostic study consisted of 2 phases: 1) primary diagnosis of the level of cognitive-affective and somatic manifestations of depression, anxiety level, nature of the world assumptions, and intensity of dysfunctional attitudes in patients with the various forms of a neurotic disorder, in the control and experimental groups, upon admission to a hospital; 2) repeated diagnosis of the level of the above characteristics of the patients took place after receiving the complete course of treatment in each group.

At the initial stage of questioning the subjects, it was determined that the sample consisted of the people with different educational levels. Therefore, in the course of further statistical analysis, the findings were further analyzed for differences in the studied parameters in the formed subgroups identified on this basis: V-subjects with higher education (46.7\%), Ssubjects with secondary professional education (31.8\%), and O-subjects who have graduated from general education institutions $(21.5 \%)$.

The findings of a statistical analysis of emotional state and cognitive attitude parameters of the patients before and after taking treatment in a hospital show that:

1) the dynamics of the anxiety and depression level, intensity of dysfunctional attitudes, nature of the world assumptions of the patients with neurotic disorders, which standard regimen of drug treatment was supplemented with rational psychotherapy, differs from the patients receiving only drug treatment. This fact proves the effectiveness of psychotherapy in relation to the examined neurotic disorders (Table 1).

Table 1. Comparison of the dynamics of the studied parameters in the control and experimental groups with the use of the analysis of variance

\begin{tabular}{|l|l|l|}
\hline Examined index & $\mathrm{F}$ & $\mathrm{p}$ \\
\hline Dynamics of cognitive-affective manifestations of depression & 0.37587 & 0.541003 \\
\hline Dynamics of somatic manifestations of depression & & \\
\hline Dynamics of anxiety & $12.34828^{*}$ & 0.000627 \\
\hline Dynamics of "world kindliness" assumption & 1.31609 & 0.253616 \\
\hline Dynamics of "fairness" assumption & 0.60730 & 0.437368 \\
\hline Dynamics of "self-image" assumption & $45.43694^{*}$ & 0.000000 \\
\hline Dynamics of "luck" assumption & $42.73136^{*}$ & 0.000000 \\
\hline Dynamics of "control" assumption & $6.97582^{*}$ & 0.009381 \\
\hline Dynamics of dysfunctional attitudes & 2.78681 & 0.097695 \\
\hline
\end{tabular}

Notes: * - statistically-valid differences

Post-hoc analysis showed that the experimental group was statistically different from the control one in the dynamics of somatic manifestations of depression, meanwhile the effect value was higher in the experimental group $\left(p \leq 0.05\right.$; value of effect $d_{\text {control group }}=-$ 
3.200; value of effect $\mathrm{d}_{\text {experimental group }}=-5.533$; $\mathrm{MS}=13.394, \mathrm{df}=118.00$ ). During rational psychotherapy, a patient learns the formal logic laws and uses these laws to seek for thought errors. Thus, a patient comes to an adequate attitude to his/her disease due to efforts of his/her own thinking; the level of fears for his/her health decreases, somatic manifestations of the disorder decrease: ahypnosia, inappetency, loss of sexual drive. Statistically significant differences in the nature of the world assumptions, such as "fairness", were identified ( $\mathrm{p} \leq 0.05$; value of effect $\mathrm{d}_{\text {control group }}=-0.46667$; value of effect $\left.\mathrm{d}_{\text {experimental group }}=1.3000 ; \mathrm{MS}=2.6740, \mathrm{df}=118.00\right)$, "fortune" $\quad(\mathrm{p} \leq 0.05$; value of effect $\mathrm{d}_{\text {control group }}=0.33333$; value of effect $\mathrm{d}_{\text {experimental group }}=1.7667$; $\mathrm{MS}=13.394, \mathrm{df}=118.00$ ). The key factor of neurotic disorders is a personal trauma/conflict as a result of adverse psychogenic effect. The world assumptions relating to the fair attitudes between "I" and the surrounding community are strongly affected by a psychological trauma. The individual's belief in the unfair distribution of events that happen to people and his/her inability to prevent difficult events by own efforts increases. Sense of own vulnerability increases too. Rational psychotherapy is focused on recovery of the world assumptions, thereby it contributes to the process of coping with trauma/conflict, decreasing the disorder manifestations, and facilitating the patient mental state. A high level of the studied parameters in the experimental group proves the effectiveness of psychotherapy.

2) There are significant differences in the dynamics of the depression level and changing nature of the world assumptions in patients with the different forms of a neurotic disorder due to the effect of rational psychotherapy. Apparent positive effect in regard to cognitive-affective manifestations of depression $\left(\mathrm{p} \leq 0.05\right.$; value of effect $\mathrm{d}_{\mathrm{CTDR}}=-5.350$; value of effect $d_{\text {CTDRa }}=-8.400$; value of effect $\left.d_{\text {NEVR }}=-4.300\right)$, and "world kindliness" assumption $\left(p \leq 0.05\right.$; value of effect $d_{\text {CTDR }}=1.2000$; value of effect $d_{\text {CTDRa }}=2.2000$; value of effect $\mathrm{d}_{\mathrm{NEVR}}=1.5000$ ) was obtained in the group of patients with the diagnosis of "Mixed anxiety and depressive reaction induced by adjustment disorder." This pathology is characterized by inability of an adequate response to the surrounding community conditions, occurrence of inappropriate actions, contraction of the individual's social contacts, changing his/her social activity. The consequences of the above include mood swing, development of the disorder. The coping mental capacities are reduced in the people with adjustment disorders, they need a longer time to adapt to the changes occurred (6 months -1 year). Rational psychotherapy is designed in such a way that it helps patients to realize their problems in less time and change their attitude to them. Focused on depressive dysfunctional attitudes, it strengthens alternative thinking, builds new standards of behavior (adaptive in its nature) due to the new forms of thinking. Mood background changes (increases), therefore, the depression manifestations are reduced.

3) In response to rational psychotherapy, dynamics of cognitive-affective ( $p \leq 0.05$; value of effect $d_{v}=-9.727$; value of effect $d_{s}=-3.941$; value of effect $d_{o}=-5.500$ ) and somatic manifestations of depression $\left(p \leq 0.05\right.$; value of effect $d_{v}=-6.545$; value of effect $d_{s}=-4.824$; value of effect $\left.d_{o}=-6.000\right)$, changing nature of the world assumptions $(p \leq$ 0.05 ; value of effect $d_{v}=2.8182$; value of effect $d_{s}=1.2941$; value of effect $d_{o}=-0.0321$ ), intensity of dysfunctional attitudes $\mathrm{p} \leq 0.05$; value of effect $\mathrm{d}_{\mathrm{v}}=-14.55$; value of effect $\mathrm{d}_{\mathrm{s}}=$ -0.9412 ; value of effect $d_{o}=-6.00$ ) in the college-educated patients with a neurotic disorder will have a more apparent positive effect compared to the patients who have graduated only from general education institutions. Based on the study findings, the application of rational psychotherapy methods in relation to the world assumptions can have a negative effect in these patients.

\section{Summary}


Based on the study findings, it can be concluded that the changes in the dynamics of emotional state and cognitive attitudes of the patients with the different forms of neurotic disorders have some differences.

Generally, it should be noted that there are statistically significant differences in the experimental and control groups in regard to the majority of the studied parameters. The key factor of neurotic disorders is a personal trauma/conflict as a result of adverse psychogenic effect. Rational psychotherapy is focused on recovery of the world assumptions, changing own attitude to problems, adjusting dysfunctional attitudes; thereby it contributes to the process of coping with trauma/conflict, decreasing the disorder manifestations, and facilitating the patient's mental state. After taking treatment, a high level of the studied parameters in the experimental group proves the effectiveness of psychotherapy.

The fact that the level of the patients's education significantly increases the effectiveness of psychotherapeutic measures is of special importance. The best results in the dynamics of cognitive-affective and somatic manifestations of depression, intensity of dysfunctional attitudes, somatic manifestations of depression, world assumptions, dysfunctional attitudes were observed in the patients with higher education that proves particular effectiveness in regard to this group of patients. Based on the data obtained, we can assume that cognitive biases are less sensitive to the changes, cognitive system is less plastic, sentiment of painful experiences caused by a neurotic disorder is combined with these features in the patients with a low level of education. They heavily refuse dysfunctional attitudes and resist to psychological correctional measures. Probably, that was the cause of the negative effect of rational psychotherapy in relation to patients of this group.

\section{References}

1. A.T. Beck New York: Intern. Univ. press. Cognitive therapy and emotional disorders, (1976)

2. N.D. Lakosina, M.M. Trunova, Neuroses, neurotic personality developments: clinical picture and treatment [Nevrozy, nevroticheskie razvitiya lichnosti: klinika i lechenie], (1994).

3. B.D. Karvasarsky, ed. Psychotherapeutic Encyclopedia [Psikhoterapevticheskaya entsiklopediya], (2016).

4. E.L. Nikolayev, Borderline disorders as a phenomenon of psychology and culture [Pogranichnye rasstroistva kak fenomen psikhologii i kul'tury], (2006).

5. T.M. Lavrinovich, Bulletin of Chelyabinsk State Pedagogical University [Vestnik ChGPU]. Comparative analysis of the views on the neurosis nature in non-medical psychotherapy [Sravnitel'nyi analiz vzglyadov na prirodu nevroza $v$ nemeditsinskoi psikhoterapii], 5, 80-84, (2015).

6. A. Babl et al., Journal of affective disorders, Comparison and change of defense mechanisms over the course of psychotherapy in patients with depression or anxiety disorder: Evidence from a randomized controlled trial, 252, 212-220, (2019).

7. A.A. Alexandrov, Bulletin of I.I. Mechnikov North-West State Medical University [Vestnik SZGMU im. I.I. Mechnikova]. The modern model of pathogenetic psychotherapy [Sovremennaya model' patogeneticheskoi psikhoterapii], 2(2), (2010).

8. K. Rudestam, Group psychotherapy. Psychocorrective groups: theory and practice [Gruppovaya psikhoterapiya. Psikhokorrektsionnye gruppy: teoriya i praktika], (2015).

9. A.T. Beck, Journal of consulting and clinical psychology, Cognitive therapy: past, present, and future, 61.2, 194, (1993). 
10. A. Ellis, Humanistic psychotherapy: The rational-emotive approach, (2002).

11. Y.V. Malygin, V.L. Malygin, S.A. Shamov, D.B. Tsygankov, S.S. Korsakov Journal of Neurology and Psychiatry [Zhurnal nevrologii i psikhiatrii imeni S.S. Korsakova]. Special issues. A multiple model of help-seeking behavior in patients with depressive and neurotic disorders [Mnogofaktornaya model' povedeniya patsientov po obrashchaemossti za meditsinskoi pomoshch'yu pri depressivnykh i nevroticheskikh rasstroistvakh], 119 (1), 1721, (2019). 